\title{
Genealogías performáticas y sujetos populares. Experiencias de danzas folklóricas y populares en Brasil y Argentina.
}

\author{
Lucrecia Raquel Greco \\ CONICET - Argentina
}

\author{
María Belén Hirose \\ IDES - UNSAM \\ Argentina
}

Resumen: El trabajo analiza comparativamente dos etnografías sobre danzas folklóricas y populares en Argentina y Brasil. Se propone estudiar los modos en que las características, genealogías y contextos de práctica de los géneros performáticos, afectan la manera en que los sujetos devienen performers del género que practican. El artículo busca entonces dar cuenta de diferencias y similitudes en la práctica de danzas entre sectores populares en dos casos específicos: las danzas folklóricas en un ballet de Argentina y el jongo en un proyecto social en Brasil.

Palabras Clave: Performance; danzas populares; Argentina-Brasil. 
Resumo: O trabalho analisa comparativamente duas etnografias sobre danças folclóricas e populares na Argentina e no Brasil. Propõe estudar os modos em que as características, genealogias e contextos de práticas dos gêneros performáticos afetam a forma em que os sujeitos se transformam em performers. O artigo procura dar conta de diferenças e semelhanças na prática de danças entre setores populares em dois casos específicos: as danças folclóricas num balé na Argentina e o jongo em um projeto social no Brasil.

Palavras chave: Performance; danças populares; Argentina-Brasil.

\begin{abstract}
The paper analysis and compares two ethnographies about folk and popular dances in Argentina and Brasil. It aims at understanding how the performatic genre's characteristics, genealogies and contexts of practice affect the subjects in becoming performers of the particular genre they practice. The article seeks to show differences and similarities in the practice of dance in the popular milieu through the comparative study of two cases: the folk dances in Argentina and jongo in Brazil.
\end{abstract}

Keywords: Performance; popular dances; Argentina-Brazil. 


\section{Introducción}

A partir de dos etnografías en espacios de práctica de danzas folklóricas y populares - la Escola de Jongo (Brasil) y el Ballet Viene Clareando (Argentina) - proponemos comparar los modos en que las genealogías de los géneros performáticos, los rasgos característicos de dichos géneros y su tejido organizativo afectan la manera en que los sujetos devienen performers del género que practican. Siguiendo a Citro (2009), entendemos que un género performático se caracteriza por los rasgos estilísticos (imagen corporal, forma del movimiento, calidades tónicas, usos del peso, flujo de energía, desarrollo temporal y uso del espacio), la estructuración (distribución espacial y organización del tiempo de las prácticas), y el conjunto de percepciones, emociones y significantes prototípicos (inscripciones sensorio-emotivas y significantes que la práctica promueve en la audiencia y en los performers) asociados a cada práctica.

Trabajaremos desde la perspectiva de la performance, que nos permite dar cuenta del papel productivo de las prácticas y experiencias corporales en la vida social, así como de la capacidad de agencia de los sujetos (Schechner, 2000). Entendemos a las artes performativas como prácticas significantes, en las que confluyen significados lingüísticos y sociales de los cuales éstas no son meros reflejos (Islas, 1995; Citro, 2009; Carozzi, 2011). Así, se enfatizan los aspectos comunicativos y constructivos de la acción, analizando prácticas que si bien son restauradas o repetidas también involucran la creatividad, a través del cambio producido en cada repetición. Por ello, esta perspectiva nos permite pensar cómo las performances, a través de su reiteración, son constitutivas e incluso a veces transformadoras de procesos subjetivos de los performers. En este sentido, consideramos que las performances pueden propiciar procesos de reflexividad, que habilitan la transformación y el cambio, tanto a través de las propias actuaciones como de la observación de performances generadas por otros (Turner, 1982, 1992). La posibilidad de cambio estaría dada porque las performances a menudo involucran técnicas extra cotidianas ${ }^{1}$ (Barba y Savarese, 1988), que pueden promover el desafío a prácticas habituales, dado que en estos espacios los sujetos pueden experimentarse a sí mismos de otras maneras.

Partiendo del supuesto de que la práctica de ciertos géneros performáticos promueve procesos específicos de subjetivación y que la posición social e histórica de dichos géneros afecta la manera en que se da esta promoción, dedicaremos un espacio a reconstruir aspectos de la

\footnotetext{
${ }^{1}$ Las técnicas cotidianas “...no son conscientes, están determinadas culturalmente y se basan en la ley del menor esfuerzo, son útiles en el marco de la condición social y el oficio de los individuos..., mientras que las extracotidianas no respetan estos condicionamientos habituales del uso del cuerpo, hacen un derroche de energía y se ligan a contextos de representación...” (Islas, 1995:198).
} 
genealogía de cada género (folklore argentino y jongo). Tendremos en cuenta los contextos nacionales en que se insertan, sus respectivas narrativas históricas, los marcos institucionales en que se han desarrollado, los fines que han orientado su práctica (la presentación en espectáculos, las competencias, los procesos de identificación, las actividades creativas de los sujetos), los sectores sociales que producen y se apropian del entrenamiento, las ideologías que implican, su profesionalización y alcance. Esto nos permitirá situar las narrativas de los performers dentro de este contexto más general.

Tras las genealogías, siguiendo la definición mencionada más arriba, nos focalizaremos en la descripción de cada género performático (Citro, ob.cit), y la práctica cotidiana de cada uno atendiendo también a la propuesta de Islas (1995: 235-3) de observar "el tejido organizativo que moviliza el entrenamiento y /o sus productos" y sus "modos de distribución y consumo". Realizaremos entonces una descripción de las performances en los contextos específicos de práctica (clases, talleres, entrenamientos, ensayos). Aunque este tipo de prácticas se interrelaciona con las presentaciones para audiencias, consideramos que pensar su día a día ilumina la manera en que los sujetos se sitúan para transformar sus posiciones identitarias. Incorporamos también en el análisis la relación entre las prácticas analizadas y el producto o punto de aplicación social (Islas, 1995: 235), ya que consideramos que el foco de la práctica, sea en la presentación escénica, en los certámenes, en el proceso de composición, en un proyecto social, en la revaloración de una identidad étnica, en la formación de bailarines profesionales, se encuentra presente en las dinámicas analizadas. La identificación de estos puntos de aplicación de la técnica resulta fundamental para rastrear los modos de subjetivación promovidos en los grupos.

A partir de estas presentaciones esperamos dar cuenta de los modos específicos en que cada género es practicado (experimentado, sentido) teniendo en cuenta los elementos mencionados. Damos paso a las etnografías.

\section{EL Ballet Viene Clareando}

Viene Clareando es un conjunto de personas asociadas alrededor de un ballet de danzas folklóricas argentinas, cuya práctica se encuentra focalizada a la presentación escénica competitiva. Tiene su sede en la localidad de Maquinista Savio, provincia de Buenos aires, en donde habitan la mayor parte de sus miembros. El barrio se encuentra a $48 \mathrm{~km}$. al Noroeste de la Capital Federal y es uno de los tantos poblados que creció bajo la influencia del ferrocarril; en 1959 se construyó una parada y se pusieron a la venta los terrenos a su alrededor. La mayor parte de los compradores fueron familias de escasos recursos provenientes de las provincias argentinas, atraídas por la cercanía de un gran número de establecimientos industriales y el fácil acceso 
a la Capital. Actualmente, continúa siendo una poblada popular, con la mayor parte de sus calles sin asfaltar y sin servicios básicos como agua corriente o cloacas.

El ballet fue fundado en 1992 por su actual director, Mario Salvatierra, quien era bailarín en un ballet de importante trayectoria. Incentivado por el deseo de compartir las habilidades y conocimientos que había adquirido en materia de danza, decidió empezar su propio grupo con gente de su barrio. La convocatoria de bailarines tuvo un éxito inmediato ya que los vecinos lo conocían por haberlo visto bailar desde pequeño en actos escolares. Al principio las clases se dictaban en la Escuela No 24 (donde él cursó sus estudios primarios) y en el fondo de su casa, y se financiaban por medio de una cuota que cobraba a los padres de los niños que iban a aprender con él.

En el año 1998 tras ganar los Torneos Bonaerenses ${ }^{2}$ en representación del Municipio, el ballet adquiere mayor reconocimiento y consigue que el estado municipal otorgue un sueldo al director, un lugar donde ensayar y subsidios esporádicos para adquirir vestuarios o contratar micros para las presentaciones. La relación con el gobierno local es aleatoria, debido a que los directores de cultura cambian periódicamente, quitando continuidad a la gestión; al no contar con políticas culturales definidas, cada recambio significa re-emprender el tejido de una nueva relación con el funcionario de turno para que conozca el ballet, el trabajo que realizan, sus necesidades económicas, etc., lo que hace necesario el despliegue de diversas estrategias para recaudar fondos.

En la actualidad, algunos bailarines se han sumado al director-fundador (que no cuenta con educación formal ni especial en relación a las danzas) en las actividades de coordinación, creación coreográfica y enseñanza. Estos bailarines se han destacado por sus logros en certámenes y una de ellas ha iniciado su formación universitaria en danzas folklóricas - además de organizar sus propios ballets.

Viene Clareando está conformado por el ballet infantil, el juvenil, el mayor, el grupo de adultos y los talleres. Los talleres son instancias introductorias donde se aprenden los rudimentos de las danzas luego de lo cual, generalmente, se pasa a algún ballet. Estos últimos se organizan para competir en diversos certámenes. El ballet Mayor es el más importante, sus miembros son los bailarines con más habilidades y/o experiencia, y tienen entre 15 y 35 años.

Las danzas folklóricas argentinas que forman parte del repertorio de los certámenes, remiten a una diversidad de épocas, regiones o grupos humanos que han sido asociados a la esencia nacional a través de procesos específicos para cada caso. Damas antiguas, caballeros, gauchos sureños o norteños y sus respectivas paisanas, criollos del noroeste o litoral, grupos aborígenes del

${ }^{2}$ Los Torneos Bonaerenses son competencias organizadas por el gobierno de la Provincia de Buenos Aires, en el que compiten representantes de todos los Municipios, en rubros artísticos y deportivos. 
noroeste, afrodescendientes de la época de la colonia o guerras de la independencia, etc., son representados en el escenario para recrear o interpretar diversas danzas como La Condición, la Resfalosa, el Carnavalito, el Candombe, el Chamamé, etc. El repertorio de danzas bailado en los certámenes surge de procesos históricos y políticas estatales que buscaron formas de construir argentinidad a través del folklore (Hirose, 2011). Distinguimos tres líneas de la genealogía que en la actualidad informan la manera en que se practican las danzas folklóricas argentinas: el desarrollo del criollismo-gaucho literario, el movimiento folklórico y la creación de la Escuela Nacional de Danzas Folklóricas Argentinas.

El "criollismo gaucho", remite a las apropiaciones populares de la literatura de fines del siglo XIX, que se caracterizó por tener como protagonistas a diversos tipos de gaucho. Entre las obras más importantes dentro de este canon podemos mencionar a Santos Vega en sus diversas versiones, Martín Fierro de José Hernández, Juan Moreira de Ricardo Gutiérrez y Don Segundo Sobra de Güiraldes. Los trabajos que analizan esta época muestran cómo los círculos letrados tendieron a mirar esta literatura con desdén, mientras que su difusión en los sectores populares alcanzó dimensiones inesperadas - en parte como resultado de las campañas de alfabetización acometidas por el estado argentino en los años anteriores3. Al comenzar el nuevo siglo la intervención pública de intelectuales nacionalistas 4 marca puntos de inflexión en la valoración de esta literatura y de su protagonista, el gaucho - cuya sangre y cultura mestizas eran resultado de la combinación de aportes indígenas e hispanos. Finalmente en las décadas de 1920-1930 el estado argentino, consagra al gaucho como figura étnica nacional con la sanción de leyes que celebraban su figura y la de escritores como José Hernández, consolidando la tendencia popular (Cattaruzza y Eujanian, 2003). También se ha señalado cómo esta consagración del gaucho dejaba de lado otros "tipos étnicos" como los aborígenes "puros", los afrodescendientes, y los inmigrantes (Lazzari, 2002). En este sentido las construcciones hegemónicas de la identidad nacional se distinguen del caso brasileño, donde se reivindicó desde comienzos del siglo XX una nación constituida por "tres razas": indígenas, negros y bancos (Da Matta, 1987).

El segundo proceso histórico que interviene en la conformación de un canon de danzas nacionales es el del "movimiento folklórico", entre las décadas de 1930-1960, que comprende un conjunto de actores y sectores (políticos, económicos, científicos, y artístico-culturales) que amplían el sentido de lo criollo, adicionando al gaucho otras figuras rurales como los paisanos y paisanas "mestizos", especialmente del Noroeste argentino (Chamosa, 2010). El movimiento folklórico (académico y artístico) proveyó

3 Entre los trabajos más importantes está el de Adolfo Prieto (2008) en el que reconstruye la circulación de la 
un cúmulo de conocimientos en forma de coreografías, músicas, leyendas, etc., que serían utilizados por el nacionalismo político en su diseño de políticas para incentivar la formación de sujetos nacionales. En relación a la gestión político-estatal, se destaca el primer y segundo gobierno (1945-1955) de Juan Domingo Perón que favoreció la difusión del folklore en el ámbito de la Capital Federal (Pujol, 1999). Las corrientes migratorias internas hacia la Capital, la revalorización de la cultura popular y una ideología y gestión políticas que tenían al pueblo como su principal destinatario (aumento del salario y del tiempo libre), beneficiaron particularmente al folklore musical. En el aspecto económico y con cierta independencia del sector político, las industrias culturales (especialmente el cine, la radio y la discografía) cobraron impulso alrededor del imaginario folklórico. Por su parte, es también durante este período que comienza la idea de que es necesario profesionalizar la investigación y la enseñanza del folklore, lo que se materializó en la creación de una serie de institutos, entre ellos, el que describimos a continuación.

Estas dos corrientes (lo criollo-gauchesco y la valorización de lo rural y de lo popular), confluyen al momento de la creación de la Escuela Nacional de Danzas Folklóricas Argentinas (ENDFA) en el año 1948. Entre los objetivos de la escuela estaba el de formar maestros de danza para guiar la enseñanza y devolver al pueblo su propio acervo cultural. La institucionalización de la enseñanza en un instituto de formación docente, facilitó que las danzas se afianzaran y ganaran continuidad a lo largo del tiempo y se expandieran en el territorio nacional (Hirose, 2010). Esto le permitió a la ENDFA - hoy parte de Instituto Universitario Nacional del Arte - sentar las bases para constituirse en una de las instituciones legitimadoras más prestigiosa en materia de danza. Esto se ve hoy reflejado en la presencia de sus profesores en los certámenes, donde actúan como jurados y difunden sus criterios de evaluación. Es decir, los alumnos de esa primera ENDFA son hoy docentes universitarios y jurados de competencias, espacios desde donde se reproducen los criterios legitimadores (Hirose, 2011).

Retomamos ahora las propuestas de Citro e Islas para volver al Ballet Viene Clareando, deteniéndonos sobre los estilos, la estructuración y las percepciones, emociones y significados desplegados durante el entrenamiento y las presentaciones escénicas. Las modalidades de los ensayos se fueron transformando entre los años 2004 y 2007. En los primeros años, la entrada en calor se realizaba mediante la práctica de bailes tradicionales en pareja, como zambas, gatos y chacareras, para luego seguir con las coreografías escénicas - ya sean éstas tradicionales o estilizadas. Esto fue cambiando rápidamente; actualmente, la entrada en calor de los ballets infantil, juvenil y mayor, se realiza con ejercicios de técnica de danza contemporánea, bloque que dura entre cuarenta minutos y una hora. Los factores que impulsaron y posibilitaron el cambio son diversos: una mayor presencia de ballets de danzas folklóricas con dominio de técnicas clásicas 
y/o contemporáneas aplicadas a las formas estilizadas en los certámenes, generó un contexto de nuevas exigencias. Este entrenamiento en técnicas de danzas clásicas y contemporáneas se sistematizó con la incorporación de uno de los bailarines del ballet como instructor, que contaba con experiencia previa en estas técnicas y que comenzaba sus estudios universitarios en composición coreográfica5. Además de las clases de técnica, se encargó de la composición de coreografías para la participación en la forma "estilización libre" de los certámenes. Los ensayos varían en intensidad según el momento del año y si el ballet tiene alguna presentación inminente. Hacia fin de año el director flexibiliza la exigencia de presentismo a los ensayos, ya que aumentan las ausencias de los bailarines por complicaciones en el trabajo o en el estudio. En ocasión de competencias importantes, los fines de semana son explotados al máximo, teniendo ensayos de más de 12 horas. Durante el verano de 2007 asistimos a los ensayos para la participación en el certamen de Tandil, y observamos un adelgazamiento general, como consecuencia de la intensidad del entrenamiento corporal. Podemos notar así los modos en que el entrenamiento para competencia afecta a las corporalidades que, como consecuencia de los cambios en los estilos, se estilizan ${ }^{6}$. Sin embargo, esta estilización corporal no es siempre buscada de manera consciente, e incluso a veces se marca la tensión con los cuerpos de las paisanas que deben representar en el estilo tradicional.

La referencia a estilos corporales de grupos étnicos específicos está ligada a las necesidades de representación para la competencia, especialmente para el rubro tradicional7 donde se pide respetar la autenticidad tradicional. Si bien la postura hegemónica en los certámenes es que dichas danzas deben basarse en coreografías documentadas, es decir, en el registro escrito y publicado de las danzas de antaño (Hirose, 2011a), los ballets recurren a la mímesis para alcanzar un estilo adecuado. Por ejemplo, en ocasión de preparar un carnavalito, danza asociada a la cultura coya del Noroeste argentino, el director por un lado leía las indicaciones de un manual de danzas, a la vez que les indicaba a los bailarines imitar la cadencia de los inmigrantes bolivianos coyas ${ }^{8}$. Esta referencia, sin embargo, no aparece como una manera de reclamar presencias o saberes silenciados en el relato nacional argentino, como ocurre con otras agrupaciones de danza folklórica que articulan el discurso sobre su práctica en la reivindicación de los indígenas y

\footnotetext{
5 La historia de este joven es muy curiosa ya que si bien era un buen bailarín, estuvo dos años de "suplente". Me contó que para poder adquirir la postura folklórica, Mario lo hacía practicar con dos latas llenas de arena en los brazos.

${ }^{6}$ Entendemos aquí por estilización de los cuerpos una tendencia a la contextura delgada, fibrosa y con poca materia grasa propia de las estéticas y los cuerpos entrenados en las técnicas de danza clásica y contemporánea occidentales.

7 Los certámenes en los que participan están organizados en tres rubros: tradicional, estilizado raíz y estilizado libre. El tradicional se basa mayormente en compilaciones escritas y publicadas, lo que expresa en gran parte el academicismo de la práctica; las versiones estilizadas incorporan diversas técnicas especialmente de las danzas clásicas y contemporáneas.

8 En el municipio al que pertenece es uno de los centros donde ha tenido destino la inmigración boliviana, que en gran parte está formada por el grupo étnico Coya.
} 
afro al folklore argentino (Benza Solari et.al, 2012)9 ${ }^{9}$ Recordemos que el mundo de los certámenes está en gran parte legitimado en las prácticas de la ENDF, hoy IUNA, que respondió a los dictados de una política estatal de nacionalización que no tenía en su centro la visualización de estos aportes. Posiblemente por el mismo motivo, los bailarines concurren a los eventos sociales (no competitivos) de danza, como las peñas, con ropa de moda, ya que el atuendo tradicional o el vestuario estilizado es exclusivo para el escenario $^{10}$, lo cual es una diferencia significativa con respecto a lo que veremos en la Escola de Jongo.

Terminada la entrada en calor, se ensayan las coreografías, ya sean tradicionales, o de estilización. En estas ocasiones el director suele tomar posesión de la palabra para explayarse sobre el sentido que busca transmitir a través del baile; en una oportunidad, explicaba que había elegido una chacarera de Horacio Banegas que, a diferencia de las tendencias actuales, volvía a los formatos musicales originales. Por eso - proseguía- la coreografía buscaba representar el nacimiento de esta danza en los patios de Santiago del Estero, y esa era la razón por la que en un momento de la coreografía se separaba una pareja y bailaba "en el fondo”, por detrás del grupo coreográfico principal. Nos aclaró que hacía un énfasis sobre el contenido de la letra, para que los bailarines "lo sientan" y pudieran interpretar lo que bailaban. Porque, continuaba su disquisición ante una audiencia que lo escuchaba atentamente, el compromiso del artista estaba en el contenido de su mensaje; al contrario, hoy en día la música de la radio le parecía vacía. "Pero es divertida" acotó un bailarín y acompañado por el resto corearon el jingle de una publicidad "clavo que te clavo la sombrilla". Hubo una risotada general, a la cual el director se unió, afirmando el beneficio de la diversión, pero insistió en que sería positivo que también se abrieran espacios para otras músicas, que muestren el compromiso del artista. Aparecían aquí valores asociados a los ancestros, cuyas raíces se encuentran en el interior del país, fuente fundamental de la esencia nacional para los folkloristas académicos.

En los relatos de los bailarines, los ensayos aparecen como un tiempo / lugar de distensión con respecto a sus rutinas. Esto puede deberse a las cualidades catárticas de la danza, que ha sido un tema ampliamente explorado en la bibliografía específica, destacándose los efectos terapéuticos del movimiento rítmico (Spencer, 1985). En efecto, al referirse al ballet muchos bailarines señalaron al efecto benéfico sobre sus vidas cotidianas: "Es como que se te olvida todo, tenés un problema, venís acá y chau; salís y te volvés a acordar, pero acá es como que nada." Por otra parte, el color emocional aparece destacado en las narrativas sobre sus presentaciones escénicas. Cuando conversamos con los bailarines preguntándoles cuál era el

9 Otro caso, aún sin analizar, es el postítulo en danzas folklóricas de la ciudad de Córdoba, dirigido por la Lic. Karina Rodriguez

${ }^{10}$ Existen ciertas agrupaciones denominadas "tradicionalistas" que sí recurren al atuendo tradicional para participar de las peñas. Sin embargo, estas agrupaciones no suelen participar del circuito de certámenes. 
momento que recordaban como el más feliz dentro de su experiencia-, hacían referencia a su participación en el certamen de Pre Cosquín ${ }^{11}$, donde experimentaron lo que en términos de la teoría ritual de Turner se conoce como communitas, en sus propias palabras, Cosquín era el momento cúlmine "por la energía" "no sé, tendrías que estar para entenderlo, es el escenario", "por la amistad de ese momento, estábamos muy unidos" (entrevistas a bailarines). El énfasis en la amistad y la metáfora del ballet como una gran familia eran las principales referencias a la importancia del ballet en la vida de los bailarines.

Si bien nuestro ballet, como la mayor parte de los que participan del circuito de certámenes ${ }^{12}$, tiene como principal motivación la participación en certámenes, la danza en sí no sería el único punto de aplicación social (Islas, 1999). Aunque no está organizado formalmente como una agrupación para formar ciudadanía, esto aparece en el discurso del director y de los padres cuando sostienen que las actividades allí realizadas mantienen a los jóvenes alejados de la calle, donde estarían expuestos a males como el consumo de drogas ilegales o alcohol. Estas motivaciones de la práctica son comunes en diversos espacios de prácticas artísticas entre sectores populares en América Latina (Hirose, 2013), como veremos también, y de forma más marcada, en el caso de la Escola de Jongo, como veremos a continuación.

\section{La Escola de Jongo}

La Escola de Jongo tiene su sede en el morro de Serrinha, favela/comunidade comunidad situada en Madureira, zona norte de la ciudad de Rio de Janeiro - que, como muchas otras favelas del entorno, es afectada por la presencia de facciones del narcotráfico y el enfrentamiento entre éstas y la policía. La Escola fue creada en 2001 por la ONG Grupo Cultural Jongo da Serrinha, -grupo de artistas locales y no locales dedicados a diversas artes populares y al jongo, género performático afrobrasileño que involucra canto, danza y percusión- cuando estos percibieron la "necesidad" de que el jongo continuase siendo practicado y fuese conocido por más personas, más allá de las familias jongueiras. Asimismo, la Escola enmarca su práctica como un proyecto social ${ }^{13}$, donde la práctica contribuiría a cambios en las vidas de las personas que de ella participan. Los docentes y coordinadores pedagógicos consideran que los objetivos del proyecto son la formación de los niños como jongueiros y ciudadanos, alejando a los niños de la posibilidad de involucrarse con el narcotráfico.

\footnotetext{
${ }^{11}$ Cosquín es una ciudad de la Prov. De Córdaba donde se lleva a cabo el Festival de Cosquín, el más convocante, comercial y masivo del folklore argentino. El Pre-Consquín es un certamen de "nuevos" valores, cuyo premio central consiste en compartir escenario con artistas ya consagrados.

12 Para una descripción más acabada de dicho circuito se puede consultar Hirose (2011b).

13 La lógica de los proyectos sociales se relaciona a la concepción de la cultura como recurso (Yúdice, 2002).
} 
Entre las paredes de la Escola -pintadas de "verde esperanza, y blanco paz” en homenaje a la Escola de Samba local, Imperio Serrano- se dictan todos los días hábiles del ciclo lectivo oficial talleres de Jongo y expresiones estéticas afrobrasileñas, folclóricas o "populares" como el Maracatú, el Griô, la Capoeira, entre otras. Estas actividades varían según el año, los financiamientos y las circunstancias dadas en el difícil mundo del trabajo en proyectos artístico sociales en regiones periféricas. Algunas actividades también son limitadas por la actividad del narcotráfico y los frecuentes enfrentamientos entre facciones del tráfico y entre éstas y la policía.

La Escola es un Ponto de Cultura ${ }^{14}$, por lo cual recibe un financiamiento básico del Ministerio de Cultura, y está habilitada para recibir recursos de empresas privadas a través de la Ley de Incentivo a la Cultura, que desvía recursos privados a través de los impuestos para proyectos sociales. También cuenta con subsidios de Organismos Multilaterales y donaciones. Estos recursos permiten pagar salarios a los docentes, adquirir materiales y solventar diversos gastos. El promedio de participantes es de aproximadamente 15 niñas y niños por turno.

Los niños que asisten a los talleres son vecinos de Serrinha, de extracción popular y en su mayoría negros. Como la mayoría de los docentes y trabajadores de la Escola se consideran a sí mismo negros, priorizando esta categoría por sobre la de moreno o mulato, resolvimos usarla para describir contextualmente esta posición de sujeto. Gran parte de los docentes, coordinadores y colaboradores de la Escola no residen en Serrinha, habiendo comenzado a trabajar allí por afinidad. En su mayoría son negros (negros, morenos y mulatos) que poseen formación universitaria o técnica en carreras universitarias o terciarias (educación física, música, danzas populares), pertenecen generalmente a extracciones medias-populares, viven en la periferia o en barrios populares de la ciudad y provienen de familias que ya valoraban positivamente la identidad negra, en sus áreas de trabajo (generalmente artístico o intelectual), religión u ocio (candomblé, umbanda, samba, Jongo). Los docentes, coordinadores y colaboradores de la Escola blancos suelen proceder también de extracciones medias, poseen escolaridad universitaria y valoran altamente las tradiciones afrobrasileñas.

Aunque en la Escola se practica jongo y otras danzas populares, nos enfocaremos en la genealogía del primero, que es el más importante. Creado por los grupos bantú de África Meridional, esclavizados para trabajar en las haciendas de café entre los siglos XVI y XIX, el jongo se practica hasta hoy en periferias de ciudades y en regiones rurales de los estados de Río de Janeiro, Sao Paulo, Espíritu Santo y Minas Gerais, especialmente en fiestas de santos católicos y divinidades afro brasileras (sobre todo de Umbanda) o para conmemorar la fecha de la abolición de la esclavitud (IPHAN, 2007). El

14 Los Pontos de Cultura son espacios de producción artístico-cultural desarrollados por la sociedad civil, que obtienen apoyo institucional y financiamiento del Ministerio de Cultura para llevar a cabo sus actividades. Desde el 2011, el programa se ha replicado en Argentina con resultados diversos. 
género se incluye entre las tantas manifestaciones musicales y dancísticas que fueron habituales entre los esclavos en Brasil, como la capoeira y el maculelê, donde se ponderaban habilidades en el trabajo rural y en la confrontación física, y se practicaban la poética y el canto basados en la improvisación y el desafío entre cantores, junto con las respuestas del coro (Carvalho, 2000). Se ejecuta en una roda (ronda), donde un coro canta respondiendo a un solista, al ritmo del toque de tres tambores de madera y cuero. Una pareja danza en el centro de la ronda, hasta ser sustituida por otra, generalmente con el movimiento de "umbigada" (adelantamiento del ombligo).

Durante el período esclavista la ejecución del jongo en los terreiros de las principales haciendas se realizaba con el permiso de los señores, quienes se constituían en audiencia (Martins de Sousa, ob.cit: 160). Este jongo rural ingresó a la ciudad de Rio de Janeiro a partir de su presentación en teatros por dramaturgos, músicos y bailarines blancos o libertos abolicionistas y a través de los contingentes de ex esclavos que migraron a la ciudad tras la abolición.

En ese momento, el jongo desapareció de los teatros, pero continuó en Rio de Janeiro y llegó a otras ciudades con la migración de ex esclavos desde las plantaciones (De Carvalho, 2002). Los batuques de los jongueiros fueron escuchados en tono celebratorio en la ciudad de Rio de Janeiro durante tres días desde la fecha de abolición, el 13 de mayo de 1888. En el período posterior a la abolición, las letras de jongos reclamaron ante la situación de abandono sufrida por los ex esclavos, como por ejemplo, la situación de "libertad" sin acceso a tierras propias.

A lo largo del siglo XX, el jongo fue practicado en diversas haciendas y en algunos asentamientos urbanos. Durante las últimas décadas del siglo, las diversas comunidades jongueiras, movimientos sociales y grupos universitarios, se preocuparon por la preservación y revitalización de la práctica (IPHAN, 2007: 22-23). Las estrategias utilizadas fueron la creación de grupos de niños, la enseñanza del jongo y su presentación en diversos espacios públicos. Debemos tener en cuenta que en el jongo de antaño no podían participar los niños, $\mathrm{y}$, al menos hasta comienzos del siglo $\mathrm{XX}$, ser jongueiro implicaba pertenecer a una familia jongueira, sea por lazos consanguíneos o de afinidad (IPHAN, 2007).

En 2005 el jongo fue declarado patrimonio cultural brasilero por el IPHAN. Asimismo, especialmente a partir de la experiencia del Jongo da Serrinha, otras comunidades comenzaron a utilizar el jongo en "proyectos sociales" relacionados con la ciudadanía y la autoestima (Pinto Passos, 2004; Perez, 2005). Fue en este proceso que el jongo comenzó a expandirse fuera de las comunidades jongueiras, incluso a estados brasileños donde no era conocido anteriormente.

Puede notarse que a lo largo de su historia el jongo ocupó en reiteradas circunstancias el lugar de espectáculo para un público blanco (en las 
haciendas y en los teatros), y se ligó también a procesos de lucha política (la resistencia a los amos, la abolición y luchas por la igualdad). Estas dos características están presentes en muchos grupos de jongo contemporáneos. Debemos tener en cuenta en esta genealogía del jongo su lugar en la construcción de la "cultura popular"15 de Brasil. El género es considerado parte de ésta por los participantes de la Escola de Serrinha, a la vez que suele ser categorizado como una manifestación folclórica, ejecutándose en compañías de danza dedicadas al folclore. Así, la distinción entre el jongo como manifestación folclórica o de cultura popular no presentaba contradicciones para los sujetos, aunque, estos siempre preferían hablar en principio de "cultura popular". Por último, en la bibliografía y en los testimonios en los que nos basamos para esta genealogía, no se encuentran referencias al jongo como danza de folclore academizada a través de su transcripción en textos impresos, sino a su práctica en otros contextos (bailes de los esclavos, presentaciones en teatros, reuniones), lo cual contrasta con las prácticas del "folclore" argentino.

Entremos nuevamente a la Escola para describir las prácticas. Aunque los entrenamientos difieren en cada uno de los talleres y según los profesores, algunos rasgos generales pueden ser apuntados. Por un lado, todos ellos se orientan a la enseñanza y práctica de jongo y danzas y músicas populares, buscando introducir en los procesos de enseñanza aprendizaje dinámicas ligadas a la "cultura popular", reconociendo el saber de maestros locales y alumnos. Los géneros performáticos practicados en la Escola son en todos los casos prácticas tradicionales (que se legitiman haciendo referencia a su pasado), que a su vez siempre involucran la espontaneidad y la improvisación dentro del lenguaje de cada género, características estas últimas asociadas en general a las danzas populares brasileras. Los saberes que se reivindican son seleccionados por cada docente: aunque todos ellos valorizan saberes acerca del pasado, de las prácticas populares actuales y del jongo, los docentes más jóvenes también consideran otras prácticas dancístico musicales de los niños que suelen ser rechazadas por las docentes mayores, como el funk carioca ${ }^{16}$. Este género es tomado con cautela por estas últimas, por tratar temas relacionados con la violencia, el narcotráfico y la sexualidad. Mientras que los más jóvenes, cuando algún niño canta o baila funk en algún taller lo incorporan al trabajo algún movimiento, aunque no las letras. Otra característica general de los géneros performáticos practicados y de las formas de enseñanza aprendizaje y práctica es que los roles suelen ser 
rotativos, no habiendo sólo una persona que toca el tambor o que baila. Los roles solo se fijan para presentaciones específicas teniendo en claro que todos deben saber hacer todo. Asimismo, el rol del individuo solo tiene sentido en el colectivo.

En la Escola se transmite un conocimiento acerca del jongo, a la vez que se apela al conocimiento que los niños tienen sobre el género, el cual es muchas veces adquirido a partir del contacto con la propia Escola, donde se familiarizan con las narrativas del pasado y las incorporan como parte de su discurso. En algunos casos los niños también reciben este tipo de formación en sus familias, pues muchos tienen familiares que han practicado jongo o participado de la Escola de samba Imperio Serrano.

Generalmente, el taller de jongo y otros dedicados a prácticas corporales comienzan con entradas en calor lúdicas o técnicas, incorporando en este último caso herramientas de danzas clásica y contemporánea, expresión corporal, etc. Posteriormente se entrenan las performances a través de juegos, improvisaciones o composiciones y finalmente se ensaya la escena que se esté produciendo o se realiza una roda de jongo.

En la formación de la imagen corporal del jongo es fundamental la figura de los pretos velhos (negros viejos), referentes del jongo. Además los docentes estimulan a los niños a usar peinados "negros" o el cabello largo y suelto en las niñas dentro y fuera de escena. Sin embargo, los niños no utilizan peinados especiales, y sus estilos varían ampliamente: hay niños que se tiñen el pelo de rubio o lo planchan, y algunos niños (especialmente niñas) que sí se hacen peinados “negros” (trenzas pequeñas, rastas, rulos).

Pueden identificarse algunas percepciones y significantes prototípicos asociados a la práctica, tales como lo "ancestral" (los antepasados que ya no viven), la corporalidad de los ancianos, la importancia de la ronda, del tambor, de la historia del barrio y de los afrobrasileños en general. Los docentes suelen conversar acerca de la historia del jongo y resaltar la importancia de la tradición de la Escola y del hecho de ser parte de ella. Un recurso habitual utilizado por la docente de danza de jongo es pedirles a los niños que imaginen las escenas que son narradas en los pontos (cantos) de jongo. Así, la docente sugiere escenas generalmente referidas al período del jongo rural, practicado en las haciendas. También se trabajan temas como la historia de la esclavitud, las fiestas populares o la diversidad religiosa. Los docentes buscan desligar la imagen del jongo de la religiosidad afrobrasileña para poder recibir personas de cualquier religión, aunque la presencia de la tradición umbanda es innegable.

En los entrenamientos se encuentra muy presente el sentido de la escena, el cual genera además emociones específicas. Los niños suelen responder inmediatamente a pedidos de los docentes tales como mirar al público, sonreír, hacer movimientos más grandes. De hecho, como notan los propios docentes, la concentración y atención de los niños cambia radicalmente al saberse ensayando para una presentación pública. $\mathrm{Al}$ 
aproximarse una presentación, los niños comienzan a preocuparse e interesarse por ella. Asimismo, la mayoría de las veces que los niños realizan algún comentario en torno a la experiencia de bailar tiene que ver con la danza en un espacio de presentación, y refieren a experiencias de nervios, felicidad, etc. Los niños ejercen críticas y elogios sobre su performance, e incluso se corrigen entre ellos. Aunque las críticas son direccionadas por los docentes, muchas veces son los niños los primeros en mencionarlas: "faltó canto", "faltaron palmas, sonrisas", "fue lindo", "la gente se emocionó" etc. No sostengo que sean los niños quienes generan los modelos de autocrítica, sino que estos sentidos del entrenamiento para una audiencia son rápidamente adoptados por ellos.

\section{Conclusiones}

Tras la descripción y análisis de las prácticas proponemos pensar comparativamente cómo se posicionan los grupos en tanto performers, así como los modos de subjetivación que se generan en la práctica. La comparación en experiencias en dos países distintos nos lleva a considerar a su vez cómo estas experiencias se ubican en el marco de la construcción de estados nacionales.

Hemos constatado cómo la genealogía de cada género influye y es recuperada selectivamente en la práctica presente. Así, en el caso argentino se hace referencia al pasado, al interior del país, e incluso al inmigrante boliviano para la recreación de las danzas, pero no hay una referencia al nosotros inmediato en los significantes apropiados; ningún bailarín se considera a sí mismo gaucho, criollo o coya, mucho menos soldado de la independencia o dama antigua. La identificación que procesa la pertenencia al ballet promueve valores relacionados a la amistad y la familia y se opone a los otros ballets con los cuales compiten o a la juventud expuesta "a los peligros de la calle", punto este último en que se asemeja, aunque con otro lenguaje, a la lógica de proyecto social. En contraste, en la Escola de Jongo se busca generar una identificación de los niños con la negritud y con los antepasados jongueiros. Este hecho se relaciona tanto con la propia negritud de la mayoría de los alumnos y con los vínculos con la militancia negra de los docentes, como con la constitución de los géneros folclóricos en Brasil, vinculada fuertemente a la narrativa hegemónica nacional de las tres razas, donde la etnicidad negra es reconocida como constitutiva de la nación. Así, si bien se trabaja en base a un pasado distante, relacionado a la vida en el campo y la esclavitud, se reivindica la resistencia negra y se busca resignificarla para el presente.

Por otra parte, notamos que en el caso argentino, la valorización del registro escrito como fuente de repertorios dancísticos se inscribe en una sociedad nacional que apostó tempranamente por la alfabetización de su 
población como medio de nacionalización de los inmigrantes; esto posibilitó que la cultura folklórica tradicional popular sea objetivada y transmitida en formato de libro. No resulta extraño, entonces, que las danzas folklóricas argentinas respondan en general a coreografías pre-establecidas (con la excepción del chamamé y el tango), ya sean tradicionales y compartidas por todos los bailarines de folklore, o creaciones de coreógrafos individuales. En el caso del jongo brasileño, y de muchas otros géneros folclóricos (como por ejemplo la capoeira o el samba), se destaca el saber de los mestres populares, vivos o fallecidos, que en muchas ocasiones, como en el caso del Jongo de Serrinha, son vecinos de los grupos que practican los géneros en la actualidad. Esta búsqueda de la fuente del saber en los propios practicantes se relaciona a la genealogía de los campos del folclore y la cultura popular brasilera, donde muchas prácticas culturales de las poblaciones subalternas fueron categorizadas como "cultura popular" e integradas en los imaginarios hegemónicos del Brasil de las tres razas ${ }^{17}$. En esta línea de la valorización de saberes escritos y "populares" en la genealogía de los géneros, podemos destacar la importancia que tiene en la Escola la improvisación, en contraste con la importancia de la coreografía en el ballet.

Aunque no contamos con estudios a nivel nacional para realizar generalizaciones, notamos que en el caso del Ballet, como muchos otros grupos de folklore argentino, la organización como centro cultural tiende a lo informal y la vinculación con el estado y sus gobiernos es intermitente. Esto requiere del constante esfuerzo y organización de ballet para financiar sus actividades. Mientras tanto, la Escola, como muchos otros grupos de danzas folklóricas brasileras, posee personería jurídica, y una estructura administrativa que la sostiene. Debemos tener en cuenta que en Brasil existen muchas líneas de financiamiento volcadas a las "culturas populares", además de que la forma ONG se ha hecho predominante en los barrios populares en las últimas dos décadas. Es interesante el hecho de que el programa Ponto de Cultura aplicado en Brasil desde 2005, ha sido replicado en Argentina desde el año 2011.

En este sentido, puede verse el peso de la articulación institucional y de la influencia del discurso de ciudadanización ligado a la lógica de la cultura como recurso en Brasil, cuando notamos la importancia del discurso de ciudadanía en la Escola. Tal vez, su apropiación del discurso de los organismos de financiación y las reflexiones teóricas sobre su práctica, puedan deberse en parte a esta mayor articulación institucional y la necesidad de escribir "proyectos" para obtener financiamientos. Mientras tanto, en el caso argentino, si bien aparece un discurso del ballet como lugar

${ }_{17}$ Yúdice (ob.cit:154) analiza cómo esta inclusión de la cultura popular em las narativas hegemónicas legitima mecanismos de desigualdad. Particularmente para el caso de Río de Janeiro, la política del samba actuaría para que las clases marginales de sientan parte de la nación, al tiempo en que son expulsadas del centro para los eventos masivos. 
de contención ni su práctica ni su discurso están organizados alrededor del discurso de ciudadanía.

En el caso brasileño podemos notar cómo la reivindicación del discurso de lo popular y de los saberes locales se inserta en un espacio donde más de la mitad de los docentes con estudios formales no viven en Serrinha, en cuanto en el caso argentino, a pesar de no existir una reivindicación de los saberes locales, su director y bailarines pertenecen al mismo grupo social. Debe destacarse, además, una tendencia a la profesionalización, pues si bien el director no cuenta con formación académica institucional, algunos de los bailarines que se incorporan como docentes han iniciado carreras terciarias o universitarias en danzas.

Centrémonos ahora en algunas de las experiencias subjetivas que se generan en estas prácticas. Por un lado, la importancia de la improvisación o la coreografía, del colectivo o del individuo y de los diversos modelos de corporalidad, constituyen un tipo de bailarín. En el Ballet, este se destaca por la capacidad de seguir una secuencia, y se valoran tanto las cualidades individuales de los bailarines como su cohesión grupal, en cuanto en la Escola se constituye un ejecutante que debe estar vinculado al colectivo para poder danzar o tocar y cuya apariencia debe acercarse a una figura "popular" como el preto velho. Podemos notar en el Ballet cómo la academización en Argentina supuso la incorporación de técnicas europeas de danza (clásica y contemporánea) que al estar focalizadas a los eventos competitivos moldea, aunque no se busque conscientemente, un cuerpo cada vez más estilizado y adelgazado. Mientras tanto, en la Escola, si bien se recurre en los talleres a elementos técnicos de esas danzas, la figura corporal que se reivindica es la del preto velho, cuyo valor se destaca más en el movimiento circular de las partes del cuerpo, y en el ritmo, y mucho menos en la forma física del cuerpo, que, además tiende a imitar cuerpos más morrudos. Este modelo de cuerpo se relaciona con la reivindicación de la negritud y de lo popular, aunque es a la vez el tipo de cuerpo escénico que se busca construir.

En el caso argentino, la búsqueda de ganar los certámenes configura las prácticas de los bailarines, quienes se reposicionan en su campo según los resultados de estas competiciones. En el caso de la Escola, el mayor peso es dado a la capacidad de llevar adelante una roda, y también a la valorización que el público da a sus presentaciones en escena. Debemos notar que en este último aspecto, para ambos casos, la experiencia escénica conlleva una carga emotiva más intensa: sea en los certámenes o en los espectáculos, los grupos de bailarines se reconocen a sí mismos más movilizados emocionalmente cuando exponen su trabajo.

Hemos buscado marcar cómo las prácticas son influenciadas por las genealogías de los géneros, y los modos en que estos por su parte han sido también configurados por experiencias nacionales. Asimismo, buscamos mostrar como los grupos se posicionan en estas historias, desde su particularidad, improvisando sus coreografías históricas. 


\section{Bibliografía}

BARBA, E. y SAVARESE, N. (comp.). Anatomía del Actor. México, Gaceta International School of Theatre Anthropology, 1988.

BENZA SOLARI, S.; MENELLI, Y.; PODHAJCER, A. Cuando las danzas construyen la nación. Los repertorios de danzas folklóricas en Argentina, Boliva y Perú. En: CITRO, S. y ASCHERI, P. (coord). Cuerpos en movimiento. Antropología de y desde las danzas. Buenos Aires, Biblos, 2012.

CAROZZI, M. J. Más allá de los cuerpos móviles: problematizando la relación entre los aspectos motrices y verbales de la práctica en las antropologías de la danza. En CAROZZI, M. J. Las palabras y los pasos: Etnografías de la danza en la ciudad, Carozzi, M. J. (org.) Buenos Aires, Gorla, 2011.

CARVALHO, J. J. Um panorama da Música Afro-brasileira: parte 1. Dos Gêneros Tradicionais aos Primórdios do Samba. Série Antropologia, Departamento de antropologia, Instituto de Ciências Sociais, Universidade de Brasília, 2000, p. 2-40.

CITRO, S. Cuerpos significantes. Travesías de una etnografía dialéctica. Buenos Aires, Biblos, 2009.

CHAMOSA, O. The Argentine Folklore Movement. Sugar Elites, Criollo Workers, and the Politics of Cultural Nationalism, 1900-1955. Tucson, The University of Arizona Press, 2010.

CATTARUZZA, A. y EUNAJIAN, A. Héroes Patricios y Gauchos Rebeldes. Tradiciones en Pugna. En CATTARUZZA, A. y EUNAJIAN, A. Políticas de la Historia. Argentina 1860-1950. Buenos Aires, Alianza. 2003.

DA MATTA, R. Relativizando. Uma introdução á antropología social. Río de Janeiro, Rocco, 1987.

GRECO, L. Políticas culturales y performance en proyectos artístico-sociales: un estudio comparativo entre sectores populares de Buenos Aires y Río de Janeiro. Tesis doctoral, Antropología, Universidad de Buenos Aires, 2013.

GRUMAN, M. Políticas públicas e democracia cultural no Brasil. IV Encontro de Estudos Interdisciplinares em Cultura, UFB, 2008.

IPHAN. Jongo no sudeste. Dossié IPHAN, N 5, 2007.

ISLAS, H. Tecnologías corporales. Danza, cuerpo e historia. Serie Investigación y Documentación de las Artes. México DF, Instituto Nacional de Bellas Artes, 1995. 
HIROSE, M. B. El movimiento institucionalizado: danzas folklóricas argentinas, la profesionalización de su enseñanza. Revista del Museo de Antropología. Universidad Nacional de Córdoba. 3, 2010, p. 187-194.

- Bailando las palabras: los documentos escritos en la práctica de la danza folklórica tradicional argentina. En CAROZZI, María Julia (ed). Las Palabras y los Pasos. Etnografías de la danza en la ciudad. Buenos Aires: Gorla, 2011a.

. Danzas Folklóricas Argentinas: Ritual, Historia y Comunidad. Tesis de maestria, Antropología Social, UNSAM, 2011.

LAZZARI, A. Indio argentino, cultura (nacional). Del Instituto Nacional de la Tradición al Instituto Nacional de antropología. En VISACOVSKY, S. y GUBER, R. Historia y estilos de trabajo de campo en Argentina. Buenos Aires, Antropofagia, 2002.

PEREZ, C. dos S. B. Juventude, música e ancestralidade na comunidade jongueira do Tamandaré - Guaratinguetá/SP, Imaginario. vol.11, no.11, 2005, online.

PINTO PASSOS, M. C. O jongo, o jogo, a ONG: um estudo etnográfico sobre a transmissão da pratica cultural do jongo em dois grupos do Rio de Janeiro. Tesis de doctorado, Educación, Pontifícia Universidade Católica do Rio de Janeiro, 2004.

PRIETO, A. El discurso criollista en la formación de la argentina moderna. Buenos Aires, Siglo XXI, 2006.

PUJOL, S. Historia del Baile. De la milonga a la disco. Buenos Aires, Emecé, 1999.

SCHECHNER, R. Performance. Teoría y prácticas interculturales. Buenos Aires, Libros del Rojas, Universidad de Buenos Aires, 2000.

SPENCER, P. Society and the Dance. Cambridge, Cambridge University Press, 1985 .

TURNER, V. From Ritual to Theatre. The Human Seriousness of Play. New York, Paj Publications, 1982. . The Anthropology of Performance. PAJP, New York, 1992.

YÚDICE, G. El recurso a la cultura. Usos de la cultura en la era global. Buenos Aires, Gedisa, 2002. 